\title{
Acute Median Nerve Compression by a Fragment of Hamate Bone
}

\section{Martín Ulloa Cerezales* and Uxía Blanco Sampedro}

Plastic Surgery Department, HM Modelo A Coruña, Spain

*Corresponding Author: Martín Ulloa Cerezales, Plastic Surgery Department,

HM Modelo A Coruña, Spain.
Received: March 29, 2020

Published: April 07, 2020

(C) All rights are reserved by Martín Ulloa

Cerezales and Uxía Blanco Sampedro.

\begin{abstract}
Acute median nerve symptoms are not commonly seen. Less frequent is the association with hamate fractures, which usually produce ulnar nerve symptoms. We report a case of a patient with an hamate fracture and acute median nerve injury. On surgical intervention, a bone fragment, directly responsible for the symptoms, was found inside the carpal tunnel.

Keywords: Median Nerve; Carpal Tunnel Syndrome; Hamate; Fracture
\end{abstract}

\section{Abbreviation}

CT-Scan: Computed Tomography Scan

\section{Introduction}

Acute median nerve compression is not a common injury [1]. It is still less common to appear in case of a fracture of hamate bone.

Nerve injury in fractures of the hamate usually affects to the ulnar nerve [2,3]. Despite there are some reports of median nerve compression $[4,5]$ in the literature, this association is extremely unfrequent.

This paper is a case report of an acute carpal tunnel syndrome caused by migration of a bone fragment in a patient with hamate fracture.

\section{Case Report}

A 39-year-old man manual- worker was admitted to the emergency room after a fall with trauma in his left hand during his job. On physical examination, was noticed edema in volar side of the hand and some pain with palpation over the hamate. He refers paresthesias in territory of the median nerve, without motor symptoms. There were no symptoms of ulnar nerve compression. Grind test was painless.

The CT-Scan demonstrates a fracture of the trapezius and the hook of the hamate, with significant displacement of the fragment inside the carpal tunnel (Figure 1a-1c).

We perform immediately surgical treatment for opening the transverse retinacular ligament and release the median nerve. We found the bone fragment inside the carpal tunnel in contact with median nerve (Figure 2 and 3). Nerve shows perineural haemathoma and no laceration.

In the initial hours after decompression, the patient referred improvement of the paresthesia. There were no complications of

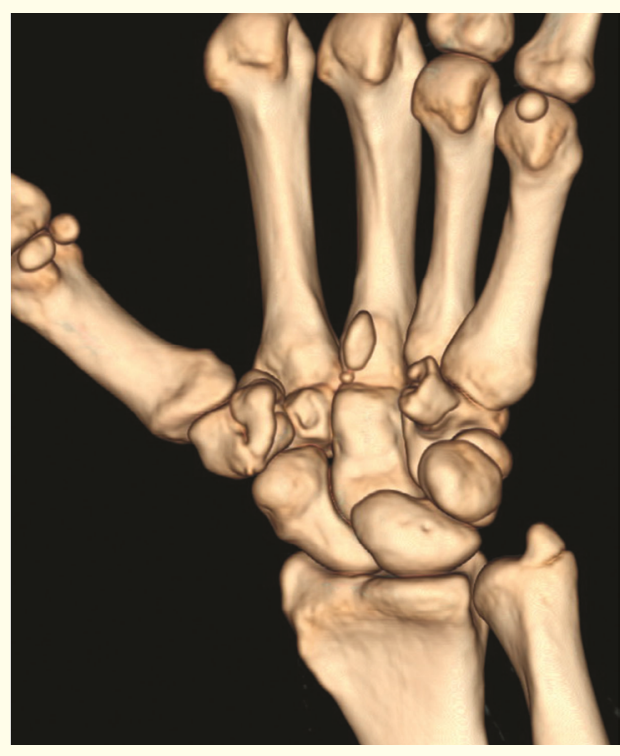

Figure 1a: 3d CT Scan AP view.

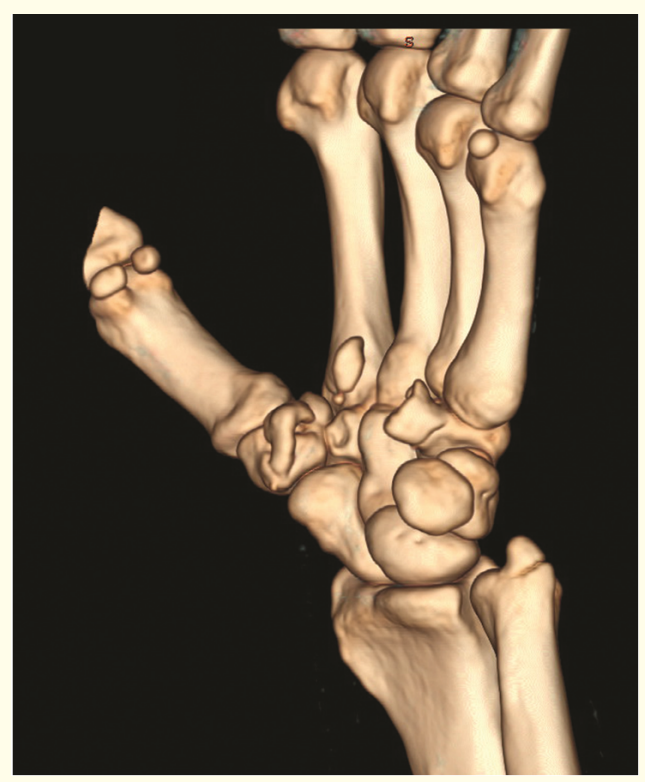

Figure 1b: 3D CT Scan oblique view. 


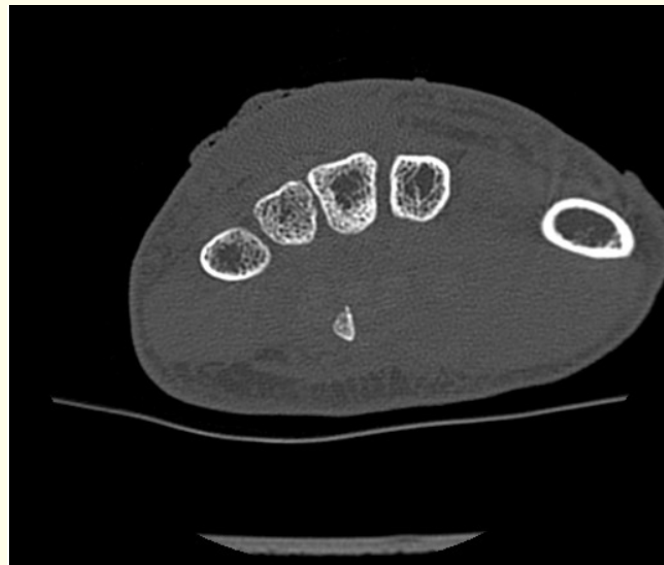

Figure 1c: CT Scan sagittal view.

Figure 1: CT- Scan images showing migration of the bone fragment inside the carpal tunnel.

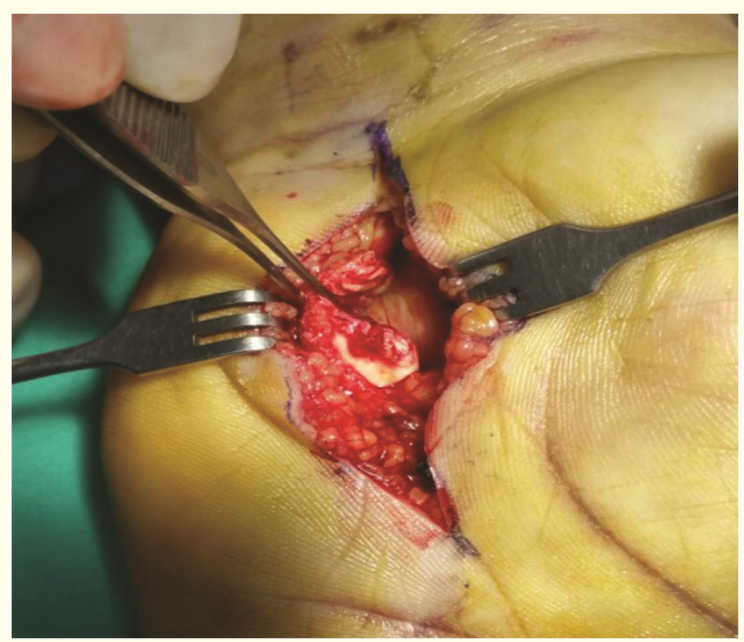

Figure 2: Opening of the transverse ligament and removing bone fragment.

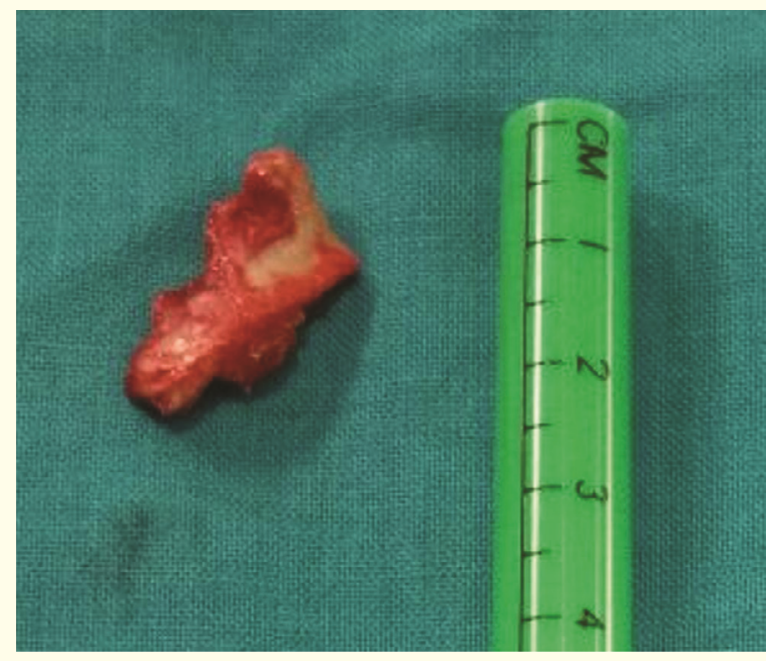

Figure 3: Photograph of the bone fragment (hook of the hamate) the surgery. Total follow up was 18 months. Paresthesias in median nerve territory improved immediately in the thumb but stay longer in the index and middle fingers. It resolved in the sixth month since the surgery.

Follow up includes two control electromyography test (EMG test): The first concentric EMG needly electromyography (3 weeks after surgery) showed slow of the sensitivity conduction velocity, $35 \%$ ) with decreased amplitude at the carpal tunnel level. Motor median nerve potential also show a decreased amplitude at the elbow level (-12\%). Ulnar nerve exploration showed no alterations.

Control EMG realized eight months after the injury, demonstrated decreased speed of conduction of the median nerve at the level of the wrist (-10\%), with normalization of motor potentials.

Follow up continued until 18 months, when the patient moves to another city and couldn't continue the follow up in our center. At that moment, paresthesias were completely resolved. Patient referred mild pain in the base of the thumb, with decreased metacarpophalangeal joint motion range, and pain with temperature changes. He could work in the same job he had before the accident (manual worker).

\section{Discussion}

There are only a few causes of acute median nerve compression and fractures are not a common association. Fractures of hamate bone produce more often ulnar nerve symptoms (sensory or motor) because its anatomical relation with the superficial and deep branches of the ulnar nerve inside the Guyon's canal.

The are some reports of median nerve compression in the literature. A literature search was conducted using Pubmed database. Key words were "median nerve", "hamate and "fracture" and we found only five articles with this association, none of them published in our country.

Usually, in fractures of carpal bones, neurological symptoms are produced by indirect nerve compression because of edema, fibrosis or haematomas $[6,7]$. In our case, the responsible of the median nerve compression was directly a bone fragment (hook of the hamate) that had migrated inside the carpal tunnel.

The carpal tunnel is an osteofibrous space, whose floor is formed by the carpal bones, and his roof is the flexor retinaculum.

The flexor retinaculum inserts: on the radial side, in scaphoid's tubercle and the trapezium, and on the ulnar side, in the pisiform and the hook of the hamate. Because of this anatomic relation, a fracture of the hamate could produce median nerve symptoms [8].

\section{Conclusion}

The ulnar nerve is the most frequently involved when a fracture of the hamate bone presents with sensory or motor symptoms. 
However, due to the anatomy of the carpal tunnel, we cannot forget it is possible that a patient with an hamate fracture could present with median nerve symptoms.

In those patients with migration of bone fragments inside the carpal tunnel on radiological exams, we must consider high risk of median nerve injury and perform urgent open carpal tunnel release.

\section{Conflict of Interest}

None of the authors have any conflict of interest.

\section{Bibliography}

1. Mc Clain EJ and Wissinger HA. "The acute carpal tunnel syndrome: nine case reports". Journal of Trauma 16.1 (1976): 7578.

2. Howard F. "Ulnar-Nerve Palsy in Wrist Fractures". Bone and Joint Journal 43A (1961): 1197-1201.

3. Foucher G., et al. "Fractures of the hook of the hamate". Journal of Hand Surgery 10.2 (1985): 205-210.

4. Sugawara 0., et al. "Fracture of the hamate hook presenting as median nerve palsy". Archives of Orthopaedic and Trauma Surgery 117.3 (1998): 73-174.

5. Manske PR. "Fracture of the hook of the hamate presenting as carpal tunnel syndrome”. Hand 10.2 (1978): 181-183.

6. Martinet X., et al. "Syndrome du canal carpien aigu. À propos d'une forme étiologique non décrite". Chirurgie de la Main 20.5 (2001): 388-390.

7. Ali M. "Fracture of the body of the hamate bone associated with compartment syndrome and dorsal decompression of the carpal tunnel". Journal of Hand Surgery 11.2 (1986): 207210.

8. Bishop AT and Beckenbaugh RD. "Fracture of hamate hook". Journal of Hand Surgery 13.1 (1988): 135-139.

\section{Assets from publication with us}

- Prompt Acknowledgement after receiving the article

- Thorough Double blinded peer review

- Rapid Publication

- Issue of Publication Certificate

- High visibility of your Published work

Website: https://www.actascientific.com/

Submit Article: https://www.actascientific.com/submission.php Email us: editor@actascientific.com

Contact us: +919182824667 